\title{
Incidence Of Persistent And Chronic Postpartum Pain And Epidural Analgesia Role: A National Survey
}

\author{
Stirparo S, Capogna G, EESOA- Rome, Italy
}

\section{Background and Aims}

Postpartum pain is very common, regardless type of childbirth or parity and affects all areas of woman's life.

This survey aimed to evaluate the incidence of persistent (2 months postpartum) and chronic (6 months postpartum) pain and the epidural analgesia (EA) role in postpartum pain development.

\section{Methods}

After ethical approval, 400 women were enrolled to

be interviewed in order to evaluate the incidence of persistent (PP) and chronic pain (CP), through validated pain scales (VAPS).

\section{Results}

319 women fulfilled the interview (Fig.1).

In nulliparous, PP was reported in $40 \%$ of spontaneous deliveries, more than $50 \%$ of episiotomy that EA reduced

to $38 \%$. PP was present in $50 \%$ of operative delivery and in $15 \%$ of $\mathrm{C}$-Section. CP was reported in $3 \%$ of spontaneous deliveries, $6 \%$ in case of episiotomy that EA reduced to $3 \%$.

$3 \%$ of $\mathrm{C}$-Section experienced chronic pain.
$25 \%$ of multiparas with a spontaneous delivery reported PP, $44 \%$ of episiotomy that EA reduced to $25 \%$.

In case of operative delivery and CS, PP was reported in $67 \%$ and $15 \%$, respectively.

CP was $2.4 \%$ of multipara with spontaneous delivery, $22 \%$ of episiotomy that EA reduced to $10 \%$. $2 \%$ of C-Section experienced CP.

No CP reported in case of operative delivery in nullipara or multipara.

\section{Conclusions}

This survey demonstrates that EA halves postpartum pain, no matter parity.

These data are important because of the impact that postpartum pain has on determining postpartum depression and suggest that EA play a role in reducing chronic postpartum pain and, consequently, its repercussions on daily life.

\section{Total sample $=319$}

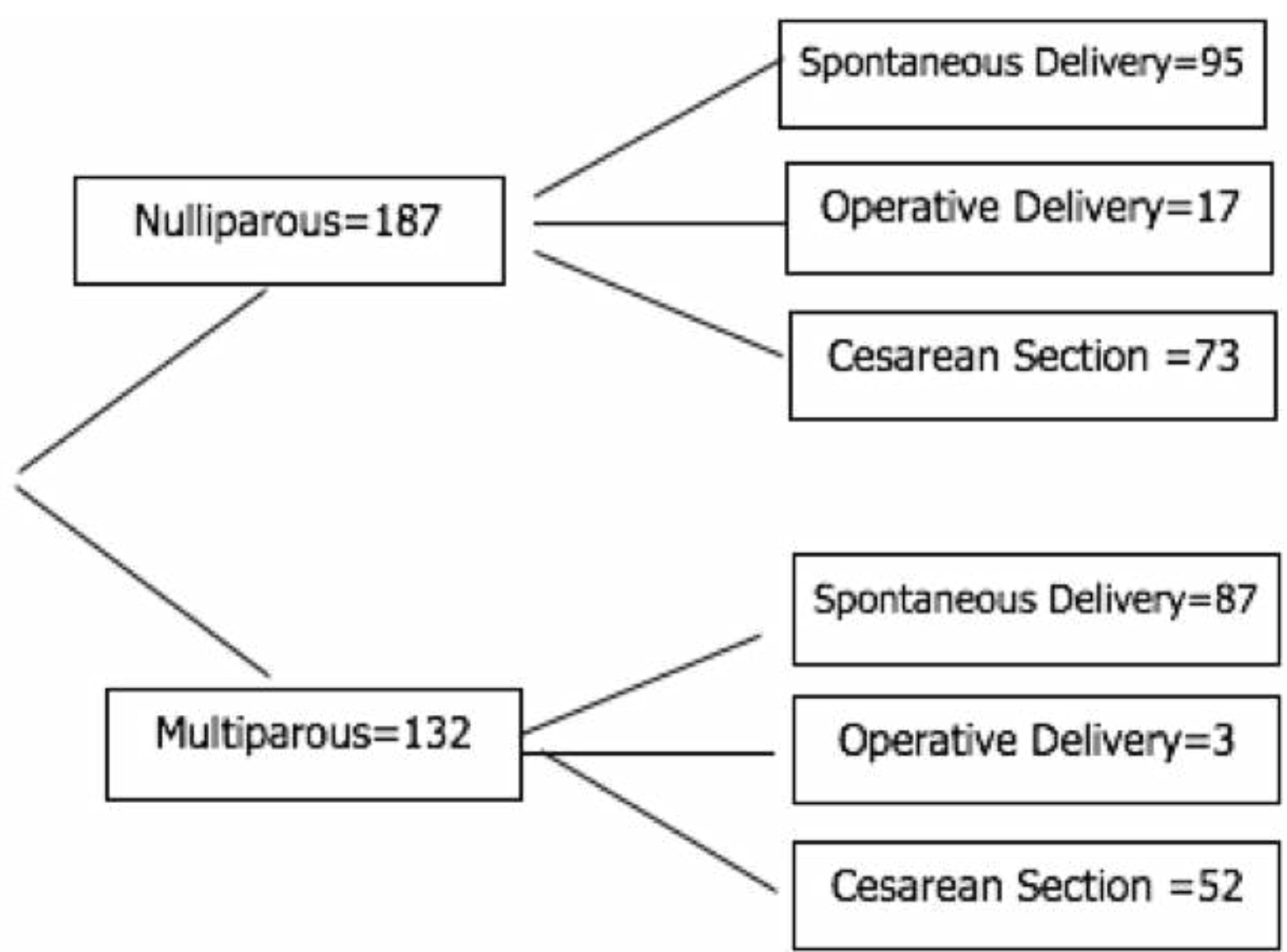

Fig.1 Women completed the survey, distribuited by parity and type of childbirth

1.Chronic pain after childbirth. Lavand'homme P. Curr Opin Anaesthesiol. 2013,26 (3):

273-277, 2013

2.Mothers' Reports of Postpartum Pain Associated with Vaginal and Cesarean

Deliveries: Results of a National Survey. Declercq E et al. Birth, 2008, 35(1):16-24

3.Severity of acute pain after childbirth, but not of delivery, predicts persistent pain and Copyright $\odot 2017$ Author Names and Contact Details postpartum depression, Eisenach JC et al. Pain 2008 15;140(1):87-94 